\title{
Approach to Realistic Mathematics Education in Teaching Calculus for High School Students: A Case of the Application of Derivatives
}

\author{
Nguyen Tien Da ${ }^{1 *}$ (1)
}

${ }^{1}$ Hong Duc University, Thanh Hoa, VIETNAM

*Corresponding Author: tiendaktn186@gmail.com

Citation: Da, N. T. (2022). Approach to Realistic Mathematics Education in Teaching Calculus for High School Students: A Case of the Application of Derivatives. International Journal of Professional Development, Learners and Learning, 4(1), ep2203. https://doi.org/10.30935/ijpdll/11832

\begin{abstract}
The purpose of the study is to systematize some core principles of Realistic Mathematics Education (RME) theory in the design of mathematics teaching so that we can design a teaching model "applying derivatives" in the topic of calculus in high school. The feasibility of the model has been verified by us through two experimental lessons in class. With the positive results, we believe that the model we propose according to RME's approach can improve the effectiveness of teaching and learning the topic of calculus at high schools in Vietnam today.

Keywords: application of derivative, teaching calculus, mathematical modeling, RME, mathematization, realistic mathematics education
\end{abstract}

Received: 23 Dec. $2021 \bullet$ Accepted: 25 Feb. 2022

\section{INTRODUCTION}

The trend of applying mathematical knowledge to solve practical problems has become a top priority goal of many mathematics educations in the world, including Vietnam. The pioneer in the theory of "Realistic Mathematics Education" is Freudenthal (1991), who believes that "math teaching needs to be linked to situations related to everyday life, to society at large in order to be valid for learners." The thought of Freudenthal (1991) paved the way for the formation of a very developed theory of mathematics education in the Netherlands, called Real Mathematical Education (RME), with two basic principles that mathematics must not only be associated with reality but also need to see mathematics as a human activity.

When considering the reality principle of RME theory, we agree with the views of Freudenthal (1991). According to this principle, Freudenthal (1991) said that mathematics must be associated with reality, the problems posed to learners must be suitable to the life of society, the conveying material must be human activities. As a result, learners can develop mathematical reasoning skills through teacher guidance to rediscover mathematical formulas or concepts. Building on the supposed foundation of RME-based learning design can help learners develop problem-solving competency.

In the high school math program, the topic of calculus is one of the important contents, including knowledge about derivatives. Derivatives have many applications in solving problems, from elementary to advanced math, and are an important tool to effectively support solving many problems that algebraic knowledge cannot access. Calculus exercises with practical and interdisciplinary content occupy a particularly important position in training a number of mathematical competencies such as mathematical reasoning ability, calculation competency, mathematical communication competency, and problemsolving competency to achieve the goal of optimizing practical human activities. Solving these types of exercises on the one hand strengthens students' knowledge of applying mathematics to practice, on the other hand, shows an interdisciplinary perspective in integrated teaching, a teaching perspective that is of great interest today.

Thus, it is necessary to innovate from the content to the methods of teaching and learning mathematics in general and teaching calculus in particular at the high school level in a way that is closely related to reality. Approaching and applying advanced math education methods into teaching practice will help students form and develop mathemathical problem-solving abilities to meet the requirements of high school students' educational goals: state and answer questions when thinking and solving exercises; use reasoning, induction and deductive methods to understand different ways of solving problems; establish a mathematical model to describe the situation, thereby providing a solution to the mathematical problem posed in the established model; ability to use mathematical tools and means to learn, explore and solve mathematical problems.

This paper systematizes a number of studies on RME theory, thereby applying this theory to the design of a learning model based on RME. Finally, based on that model, we design learning situations that 
apply calculus knowledge to solve real-life problems according to the approach of realistic mathematics education.

The research results are arranged as follows: some research results on RME theory, including the characteristics of RME, teaching, and learning principles based on RME are presented first. Then, we propose a model of lesson design based on RME, and a teaching model based on RME is also presented. The model we proposed was conducted in a pedagogical experiment at a high school in Vietnam. After that we present the discussion of the results reflected in the experimental teaching. Finally, some conclusions and recommendations are presented.

\section{OVERVIEW OF REALISTIC MATHEMATICS EDUCATION}

\section{What is Realistic Mathematics Education (RME)?}

RME is a teaching and learning theory in mathematical education first introduced and developed by the Freudenthal Institute in the Netherlands. This theory has been applied in many countries around the world such as Great Britain, Germany, Denmark, Spain, Portugal, South Africa, Brazil, USA, Japan, and Malaysia. Currently, RME theory is mainly defined by Freudenthal's (1991) view of mathematics. His two important views were that mathematics must be connected with reality and mathematics as a human activity. First, mathematics must be close to children and relevant to every day-to-day life situation. However, the word "reality" refers not only to the connection with the real world, but also to real, problematic situations in the student's mind. This means that, for problems presented to students, the context can be real-world but this is not always necessary, the context can also come from the imaginary world of the student, fairy tales, or the formal world of mathematics, as long as the problems are real in the student's mind. Lange (1996) states that such situations can also be viewed as applications or modeling. Second, he emphasized mathematics as a human activity. Mathematics education is organized as a guided reinvention (re-creation) process, where students can experience a similar process to the one in which mathematics was invented. Furthermore, the principle of reproducibility can also be inspired by informal processes or solutions. Informal student strategies can often be understood as intended for the formation of more formal processes. In this case, the concepts of mathematization serve as a guide to the reinvention process.

\section{Three Key RME Principles for Teaching Design}

Gravemeijer (1994) states that RME stems from Freudenthal's (1991) interpretation of mathematics as a human activity. Freudenthal (1991) took his starting point in the activity of mathematicians, whether pure or applied. He describes their activity as problem-solving, problem finding, and topic arrangement-whether it's a matter of math or matter from reality. According to Freudenthal (1991), the second activity-organizing mathematical activities - plays the role of the main activity. Interestingly, he sees it as a collective activity that represents a characteristic of both pure and applied mathematics. Therefore, when set "mathematics" as the goal for math education, it can include mathematics of mathematics and actual mathematics.

According to Gravemeijer (1994) mentioned by Fauzan (2002, 2013), there are three key RME principles for teaching design, namely:
1. Guided reinvention and progressive mathematizing (guided discovery and progressive mathematics).

2. Didactical phenomenology (didactic phenomena).

3. Self-developed models.

Guided reinvention and progressive mathematizing

According to the principle of regeneration, students should be given the opportunity to experience a process similar to that in which mathematics was invented. This implies that during academic instruction, students should be given the opportunity to build their own mathematical knowledge on the basis of such a learning process. This principle holds on the believe that students will learn better when they discover the concept themselves. They will be given the situated conditions to experience and see the process of how particular mathematical concepts are invented. According to this principle, the first process includes two components: activity and then the concept discovered. Here, teachers are the 'facilitator' who guides the students to invent, to discover a concept based on their observation

\section{Didactical phenomenology}

The term phenomenology can be described as an objective investigation of the logic essence and meaning of an experiment in understanding a topic (Whittles, 2007). This term is basically widely used in the fields of philosophy; nevertheless, the approach of phenomenology is also used in many other fields, especially to explore someone's mental characteristics based on experience or imagination. In the context of education, particularly in RME, the term phenomenology was first disclosed by Freudenthal (1973). Freudenthal (1983) described it as a method of studying the relationship between mathematics, history, and education. In this matter, he contrasted the term phenomena and concepts. According to him, phenomenon refers to what we want to understand, create interest in, or structure, while the concept is a thought process that organizes these phenomena. Based on both descriptions, Freudenthal (1983) then defines phenomenology as follows:

"Phenomenology of a mathematical concept, a mathematical structure, or a mathematical idea means, in my terminology, describing this noumenon in its relation to the phenomena of which it is the means of organizing, indicating which phenomena it is created to organize, and to which it can be extended, how it acts upon these phenomena as a means of organizing, and with what power over these phenomena it endows us. If in this relation of noumenon and phenomenon I stress the didactical element, that is, if I pay attention to how the relationship is acquired in a learning-teaching process, I speak of didactical phenomenology of this noumenon. (...) if "is ... in a learning and teaching process" is replaced by "was ... in history", it is historical phenomenology."

As the main initiator of RME, Freudenthal (1983) explicitly stated that the core of didactic phenomenology is a phenomenon that needs to be organized with the concept of thought. Its essence is translating the phenomenon into a problem situation that is meaningful for students and creating a need for the organization with a particular concept (Bakker, 2004). This suggests that the phenomenon presented should be eligible to be transformed into a situation problem which will then be organized. Conceptually, it is described in Figure 1 and Figure 2. 


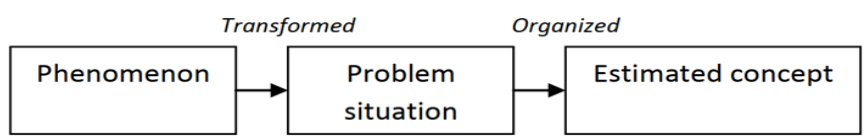

Figure 1. Early process of didactic phenomenology

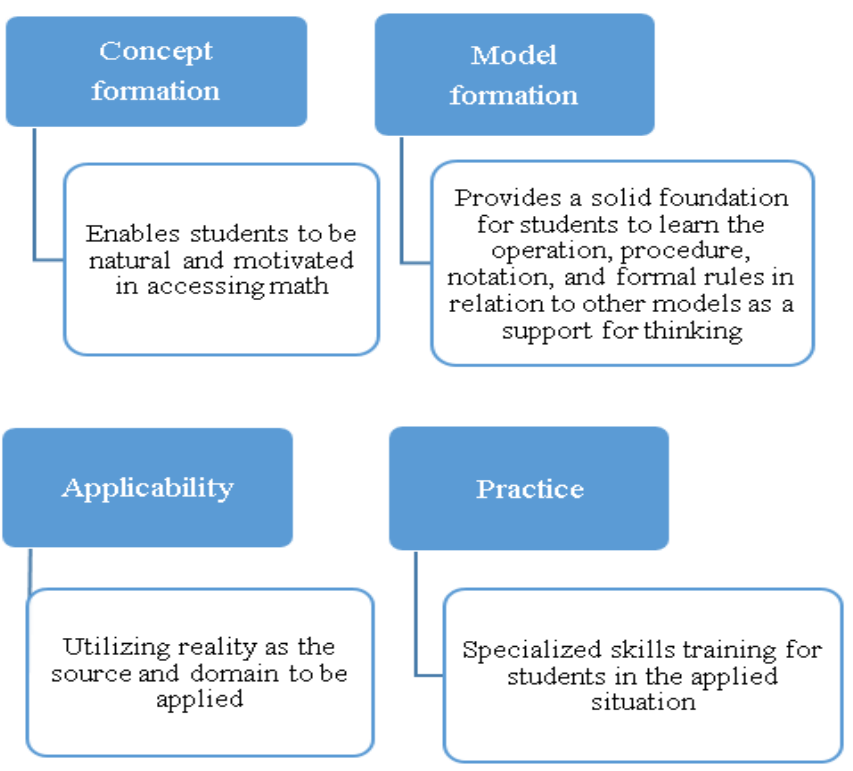

Figure 2. Four criteria of a didactic phenomenology

\section{Self-developed model}

The third key principle for RME instruction is the importance of models. This narrows the gap between formal knowledge and practical application. Following this principle, teachers must provide students with opportunities to use and develop their own models as they solve problems. At the beginning, students will develop a pattern that is familiar to them. After generalization and formalization, the model gradually becomes an entity of itself. Gravemeijer (1994) calls this process the transition from "model of" to "model of for". After transformation, the model can be used as a model for mathematical inference (Gravemeijer, 1994; Gravemeijer \& Cobb, 2006; Gravemeijer \& Doorman, 1999; Treffers, 1991). Self-developed modeling in RME theory as a precursor to "mathematical modeling" (Gravemeijer, 2004, p. 137-139). Figure 3 shows self-developed model.

\section{Five Basic Features of RME}

The combination of Van Hiele's three levels, Freudenthal's (1973) "didactic" phenomenology, and Treffers' (1978) "mathematization" process leads to the following five basic features of RME:

1. Phenomenological exploration or the use of contexts.

2. The use of models or bridging by vertical instruments.

3. The use of students' own productions and constructions or students contribution.

4. The interactive character of the teaching process or interactivity.

5. The intertwining of various learning strands.

\section{Phenomenological exploration or the use of contexts}

RME is about context, not application. The RME curriculum is built around contexts that are capable of generating powerful and flexible mathematical models. Contexts can be taken from the real world, from fiction, or from a mathematical field with which the
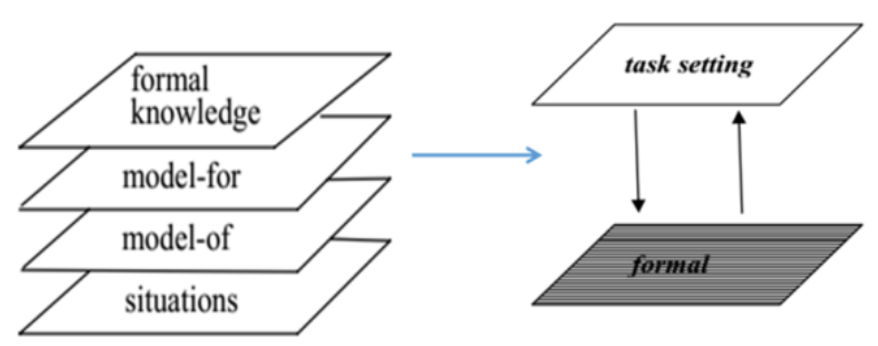

Figure 3. Self-developed modeling \& Mathematical modeling

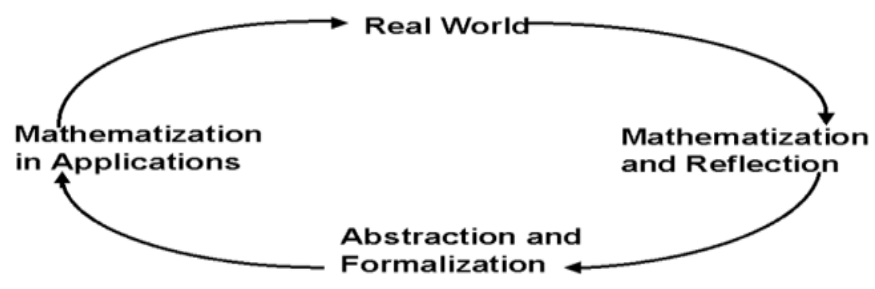

Figure 4. Concept and applied mathematization (de Lange Jzn, 1996)

student is already familiar. It is important that students are able to imagine and participate in these situations.

In RME, the starting point of instruction must be "real" for the student; allow them to immediately join the situation. This means that instruction should not begin with a formal conceptual system. The phenomena in which concepts appear in practice should be the source of concept formation. The process of deriving the appropriate concept from a particular situation is stated by de Lange Jzn (1987) as the "mathematication of the concept". This process will force students to explore the situation, find and identify relevant math content, discover rules, perform math operations, and develop a "model" that leads to a mathematical concept. By reflecting and generalizing students develop a more complete concept. Students can and will then apply mathematical concepts to new areas of the real world, and by doing so, students are reinforcing the concept. This process is called in-app mathematization (see Figure 4).

There are two types of mathematization explicitly formulated by Treffers (1987) as horizontal mathematization and vertical mathematization. In horizontal mathematization, students present mathematical tools that can help organize and solve a problem set in a real-world situation. Horizontal mathematization may include: defining or describing specific mathematics in a general context, mathematizing, constructing and visualizing a problem in terms of different ways, discover relationships, detect patterns, rules, convert a real-world problem into a math problem, and convert a real-world problem into a known math problem. On the other hand, vertical mathematization is the process of reorganization within the mathematical system itself. The following activities are examples of vertical mathematics: representing a relation in a formula, proving the regularity, refining and adjusting the model, using different models, combining and integrate models, build mathematical models and generalize.

Freudenthal (1991) states that "horizontal mathematization" involves moving from the world of life into the world of symbols, while "vertical mathematization" means moving in the world world of symbols". But he adds that the distinction between the two is not always clear-cut. Figure 5 depicts the horizontal and vertical mathematization in the mathematization cycle (Franchini et al., 2017). 


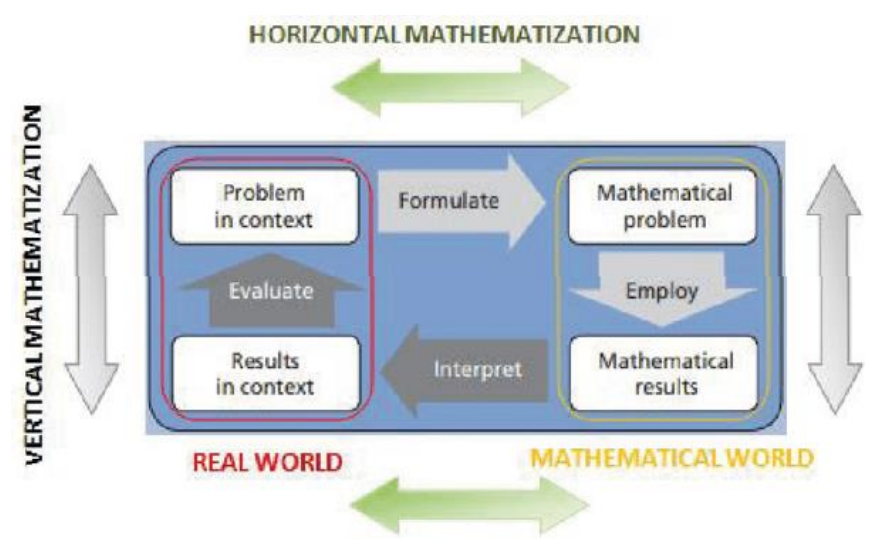

Figure 5. Horizontal \& vertical mathematization in the mathematization cycle (Franchini et al., 2017)

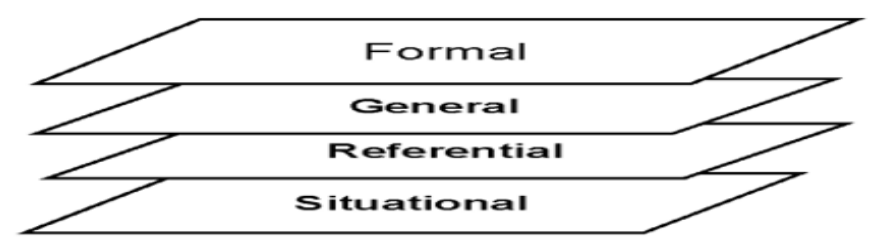

Figure 6. Levels of models in RME (Gravenmejer, 1994)

\section{The use of models or bridging by vertical instruments}

The term model refers to situational models and mathematical models developed by students themselves. This means that students develop patterns in problem solving. At first, the model is a situational model familiar to students. Through a process of generalization and formalization, the model eventually becomes an entity of itself. It can be used as a model for mathematical reasoning. The four levels of modeling in the design of RME-based lessons are depicted in Figure 6.

\section{The use of students'own productions and constructions or students' contribution}

Student-created work may be an essential part of the assessment. For example, students may be asked to write an essay, do an experiment, collect data, and draw conclusions, design exercises that can be used in a test, or design a test for other students in the class.

\section{The interactive character of the teaching process or interactivity}

Interaction between students and students and between students and teachers is an essential part of RME (de Lange Jzn, 1996; Gravenmeijer, 1994). Interaction manifests in discussion, cooperation, and evaluation. These are essential elements in a constructive learning process, in which the informal methods of students are used as leverage to achieve formal ones. Under this principle, students are engaged in explaining, debating, agreeing and disagreeing, and questioning the alternatives of their classmates and instructors or teachers.

\section{The intertwining of various learning strands}

In RME (de Lange Jzn, 1996; Gravenmeijer, 1994), integration of mathematical circuits or units is essential. It is often referred to as the holistic approach, in that regard learning chains cannot be treated as separate entities; instead, the interweaving of learning chains is exploited in problem solving. One of the reasons for forming this principle is that the application of mathematics is difficult if mathematics is taught only "vertically", i.e. if different subjects are taught separately, ignoring cross relationships.
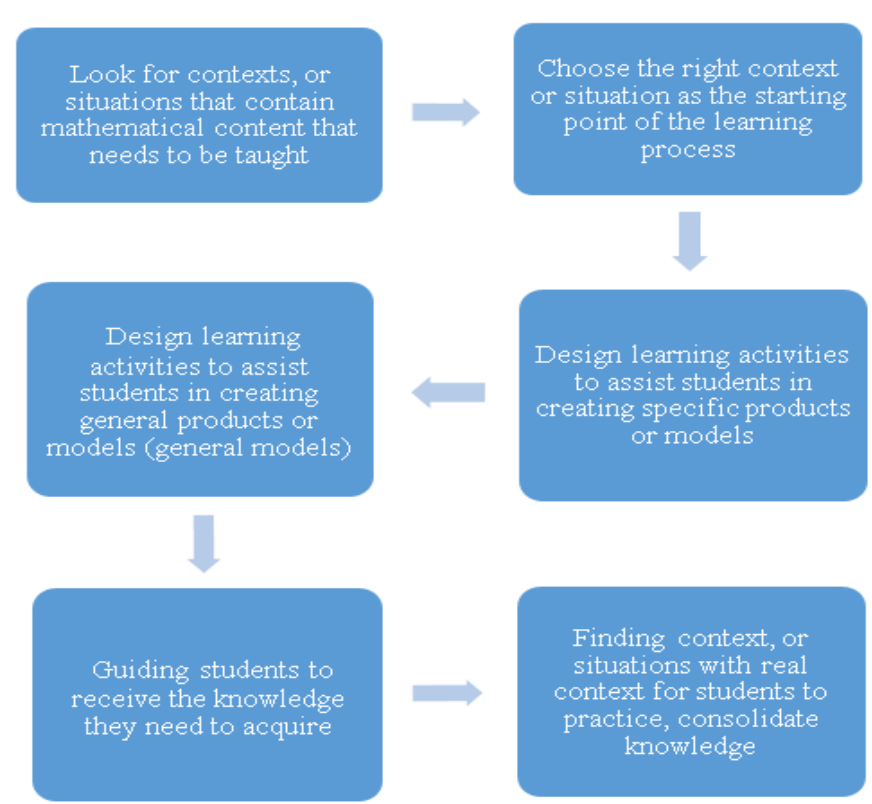

Figure 7. Design RME-based lesson

\section{RESEARCH METHODOLOGY}

\section{General Background}

RME emphasizes that learning math means that students experience a different understanding of contextual solutions at an informal level, through creating different levels, to better understand how related concepts and strategies. Modeling is an important bridge to bridging the gap between informal mathematics and formal mathematics. To make this function, models must change from a "model of" (for a particular situation) to a model that is applicable to all other types of situations but is equivalent ("model for"); In particular, the process includes the following levels (Zulkardi, 2010):

1. Situational level, where domain-specific, situational knowledge and strategies are used within the context of the situation,

2. A referential level or the level "model of", where models and strategies refer to the situation described in the problem,

3. A general level or level "model for", where a mathematical focus on strategies dominates over the reference to the context, and

4. The level of formal mathematics, where one works with conventional procedures and notations.

How to Design Realistic Mathematics Education Lesson?

Based on the characteristics of RME, principles of teaching and learning, we propose steps to design lessons base on RME, including six steps (Figure 7):

1. Step 1: Look for contexts or situations that contain mathematical content to be taught.

2. Step 2: Choosing the reasonable context or situation as the starting point of the learning process.

3. Step 3: Design learning activities to assist students in creating specific products or models.

4. Step 4: Design learning activities to assist students in creating general products or models (general models).

5. Step 5: The teacher guides the students to receive the knowledge they need to acquire.

6. Step 6: Choose similar contexts or situations for students to practice and consolidate knowledge. 
Step 1. The teacher provides reat context situations as the starting point of the learning process

\section{$\Longrightarrow$}

Step 4: Students build their own process or strategy to move from "model of" to "model for" (applicable to similar situations or contexts)

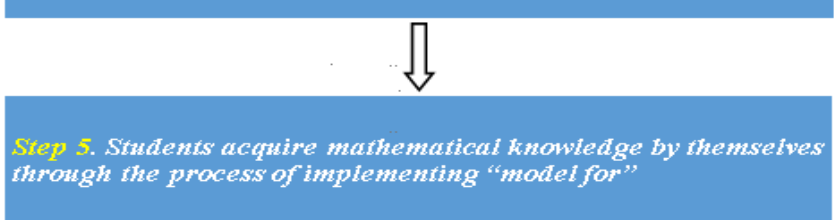

Step 8. Proposing similar contexts (homework) for students to Step 8. Proposing similor
apply learned knowledge
Step 2. Shulents investigate and analyze context or simation based on personat experience and knowledge

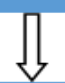

Step 3. Students self-analyze the data and sequence the information, then choose specific solutions and strategies to solve the problem (build a "modet of")

Figure 8. RME-based teaching model

Table 1. Role of steps in RME-based teaching model

\begin{tabular}{|c|c|c|c|c|}
\hline \multirow{2}{*}{ Reality situations } & \multicolumn{2}{|c|}{ Mathematization activity } & \multirow{2}{*}{ Interaction of the teaching process } & \multirow{2}{*}{ Model application } \\
\hline & Horizontal mathematization & Vertical mathematization & & \\
\hline Step 1 \& Step 2 & Step 3 & Step 4 \& Step 5 & Step 6 \& Step 7 & Step 8 \\
\hline
\end{tabular}

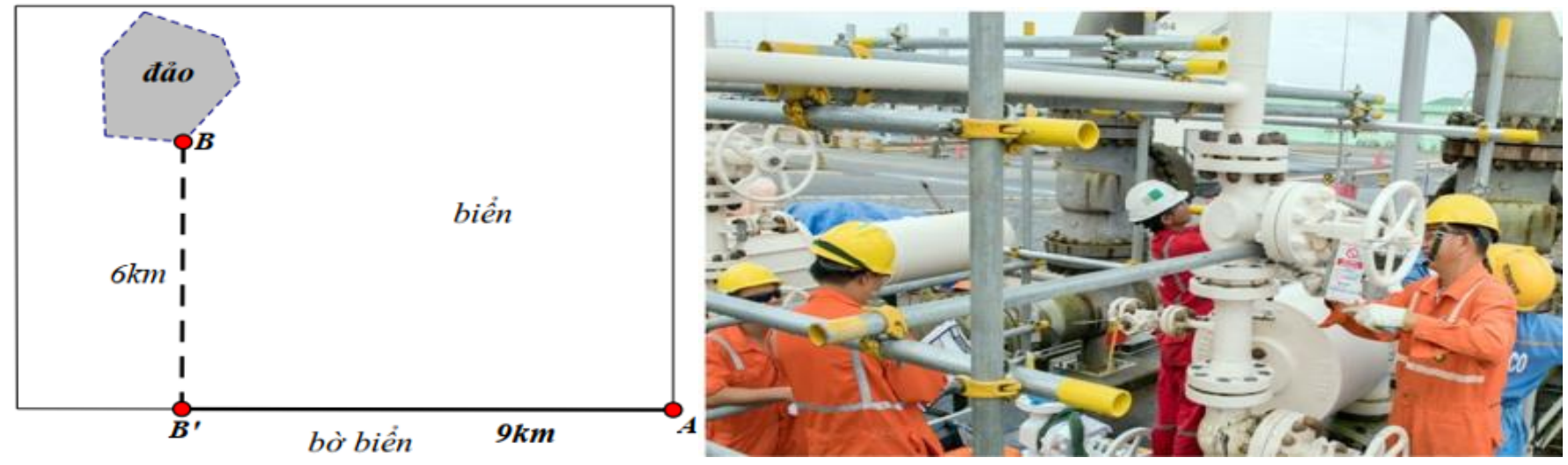

Figure 9. Pictures of the construction of a gas pipeline from the Mainland to the Nghi Sơn Island

\section{Model of RME-based teaching}

From the fundamental points of RME, we develop the RME-based teaching model, which consists of eight steps as shown in Figure 8. Table 1 shows the role of steps in RME-based teaching model.

\section{Research Procedures}

1. Selected mathematical content for experimental teaching: Application of derivatives in calculus program 12.

2. Classes used for experimental teaching: 12 C4 Nong Cong II High School, Nong Cong, Thanh Hoa, Vietnam.

3. Teaching method used for experiment: Using model of RME-based learning with a real-life situation, as follows: Nghi Son Iron and Steel Joint Stock Company wants to build a gas pipeline from Nghi Son industrial zone (point $A$ ) along the mainland before reaching a location on Nghi Son island (point $B$ ) (see Figure 9). Know that Nghi Son Island is $6 \mathrm{~km}$ from the mainland. The cost to build and install per $\mathrm{km}$ of pipeline on land is 50,000 USD, and construction under water is 130,000 USD. Assume that $B$ is a point on the ground such that $B B^{\prime}$ is perpendicular to $A B^{\prime}$.
The distance from $A$ to $B^{\prime}$ is $9 \mathrm{~km}$. How far is the location of point $M$ on land from $A$ to minimize the cost of building the pipeline from $A$ through $M$ to $B$ ? $\left(A, M\right.$, and $B^{\prime}$ are 3 collinear points).

Teaching activities are conducted in three phases:

1. Phase 1: The teacher guides and statistics the results of the students answers on the worksheets: The questions on the worksheet (From Q1 to Q5) are described in Table 2.

2. Phase 2: Teachers organize, control and guide students to solve learning situations through group work: The questionnaire for students to discuss and work in groups is shown in Table 3.

3. Phase 3: Teacher gives similar situations or contexts (homework):

a. Situation 1. A passenger car from Viet Tri to Hanoi can carry up to 60 passengers per trip. If a trip can carry $\mathrm{m}$ passengers, the fare for each passenger is calculated as VND. Calculate the number of passengers on each passenger car trip so that the garage can get the maximum profit per bus trip. 
Table 2. Questionnaire (for students) used during teacher's instruction

\begin{tabular}{lll}
\hline No & Questions & Object \\
\hline Q1 & On what quantity does the cost to install a gas pipeline above ground depend?, specify that quantity. & Suggestions for students to take the first step: \\
\hline Q2 & How is the cost of installing gas pipelines on the ground calculated?, please show that formula? & -Establish relationships between data \\
\hline Q3 & On which quantity does the cost of installing gas pipelines at sea depend?, please indicate that quantity? & -Provide a specific formula to calculate cost of \\
\hline Q4 & What formula is the cost of building a gas pipeline at sea calculated, please show that formula? & building gas pipelines on ground \& under sea surface \\
\hline Q5 & What formula is total cost that company has to spend on construction \& installation of gas pipeline? & Set up a model, give a specific formula for problem \\
\hline
\end{tabular}

Table 3. Questions for students to discuss and work in groups

\begin{tabular}{|c|c|c|}
\hline & Questions & Object \\
\hline Q6 & $\begin{array}{l}\text { Can we come up with a formula for the construction cost according to an algebraic expression of a } \\
\text { function of one variable? }\end{array}$ & $\begin{array}{l}\text {-Developing functional thinking } \\
\text {-Mathematizing practical situations }\end{array}$ \\
\hline Q7 & $\begin{array}{l}\text { Is finding the location of point } M \text { to spend on construction and installation of gas pipelines the lowest } \\
\text { related to any mathematical knowledge that you have been learning or not?, if so, please indicate that } \\
\text { mathematical knowledge? }\end{array}$ & $\begin{array}{l}\text {-Move from solving practical; requirements to solvin } \\
\text { mathematical problems; } \\
\text {-Identify strategies \& specific solutions }\end{array}$ \\
\hline Q8 & $\begin{array}{l}\text { What is the distance between two points } A \text { and } M \text {, so that the installation cost of the pipeline is the } \\
\text { least? }\end{array}$ & $\begin{array}{l}\text {-Solve math problems } \\
\text {-Convert math results to contextual results }\end{array}$ \\
\hline & $\begin{array}{l}\text { From solving the above situation, can you come up with a general model for the mathematization of } \\
\text { practical situations related to optimization factors? }\end{array}$ & $\begin{array}{l}\text { Orientation for students to build a general model } \\
\text { ("model for") }\end{array}$ \\
\hline
\end{tabular}

Table 4. Results of students' answers on the worksheets

\begin{tabular}{|c|c|c|c|}
\hline \multirow{2}{*}{ Questions } & \multicolumn{3}{|c|}{ Answer results of students in class $12 \mathrm{C} 4$} \\
\hline & Right & Incorrect & No answer \\
\hline \multirow{2}{*}{ Q1. On what quantity does the cost to install a gas pipeline above ground depend? Specify that quantity. } & 19 & 8 & 7 \\
\hline & $55.88 \%$ & $23.53 \%$ & $20.59 \%$ \\
\hline \multirow{2}{*}{ Q2. How is the cost of installing gas pipelines on the ground calculated? Please show that formula. } & 24 & 6 & 4 \\
\hline & $70.59 \%$ & $17.65 \%$ & $11.76 \%$ \\
\hline \multirow{2}{*}{ Q3. On which quantity does the cost of installing gas pipelines at sea depend? Please indicate that quantity. } & 27 & 4 & 3 \\
\hline & $79.41 \%$ & $11.76 \%$ & $8.83 \%$ \\
\hline \multirow{2}{*}{ Q4. What formula is the cost of building a gas pipeline at sea calculated? Please show that formula. } & 31 & 2 & 1 \\
\hline & $91.18 \%$ & $5.88 \%$ & $2.94 \%$ \\
\hline \multirow{2}{*}{ Q5. What formula is total cost that company has to spend on construction \& installation of the gas pipeline? } & 32 & 1 & 1 \\
\hline & $94.12 \%$ & $2.94 \%$ & $2.94 \%$ \\
\hline
\end{tabular}

b. Situation 2. Mr. Thanh's family raises shrimp with a pond area of $100 \mathrm{~m}^{2}$. In the last shrimp crop he raised with a density of $1 \mathrm{~kg} / \mathrm{m}^{2}$ of seed shrimp and the shrimp yield when harvested was about 2 tons of shrimp. With many years of experience in shrimp farming, he said that for every $200 \mathrm{~g} / \mathrm{m}^{2}$ of seed reduction, the shrimp yield would be 2.2 tons of shrimp. So, how many kg of seed shrimp do you have to stock next season to achieve the largest shrimp harvest? (Assuming no disease, loss when raising shrimp seed).

c. Situation 3. A shopping mall sells 2,500 televisions per year. The cost of storing it in the warehouse is 100,000 VND per TV per year. To order, the fixed cost per order is 200,000 VND plus another 90,000 VND per TV. How many times should the center order each year and each time to minimize inventory costs? Know that each order is only half of which is displayed in the store.

\section{Data Analysis}

The research data was analyzed by descriptive statistics and from the students' answers recorded on the worksheets, we used qualitative analysis to make comments and conclusions. Data analysis was performed using Excel, the results were summarized in tables.

\section{RESULTS}

The results of the students' responses are shown in Table 4. Table 5 shows the students' products in group activities. The results and products of the groups are shown through the actual pictures in the experimental classroom in Figure 10-Figure 13.

\section{DISCUSSION}

Statistics of students' study sheets, we find that with the first and second questions, some students have difficulty and do not fully understand the situation appearing in the problem, the result is: with question number 1 , only 19 students answered correctly (accounting for $55.88 \%$ ), 8 students answered incorrectly (accounting for 23.53\%) and 7 students had no answer (accounting for about 20.59\%); with question number 2 , the results are better but not significantly, there are 24 students giving correct answers (accounting for 70.59\%), 6 students giving incorrect answers (accounting for $17.65 \%$ ), and 4 students did not answer (accounting for 11.76\%). With questions 3 and 4, after students were analyzed and guided by the teacher, the number of correct answers increased, respectively (79.41\% and $91.18 \%)$, and the number of incorrect answers decreased (to $11.76 \%$ and 5.88\%) significantly. Moreover, the percentage of students who did not give an answer also decreased from $20.59 \%$ to $2.94 \%$. 
Table 5. Students' products in group activities

\section{No Discussion questions}

Q6 Can we come up with a formula for the cost of pipelining by an algebraic expression of a function of one variable? If so, what is the variable in that expression?

Q7 Is finding the location of point $M$ so that the cost of pipeline construction is lowest is related to any mathematical

knowledge that you have been learning or not? If so, please indicate that mathematical knowledge.

Q8 How many kilometers from $A$ is $M$ to minimize the cost of constructing the pipeline?

Q9 From solving the above situation, can you come up with a general model for the mathematization of practical situations related to the optimization factor? If so, please provide the model.

Products of the groups

Figure 7, Figure 8, Figure 9, \& Figure 10

Figure 7, Figure 8, Figure 9, \&

Figure 10

Figure 7, Figure 8, Figure 9, \& Figure 10

Figure 12

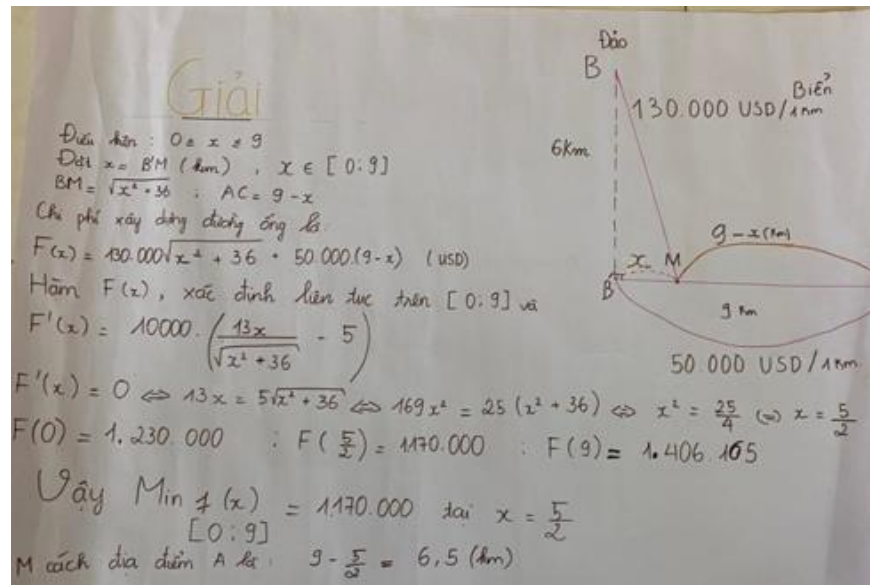

Figure 10. Products of group 1

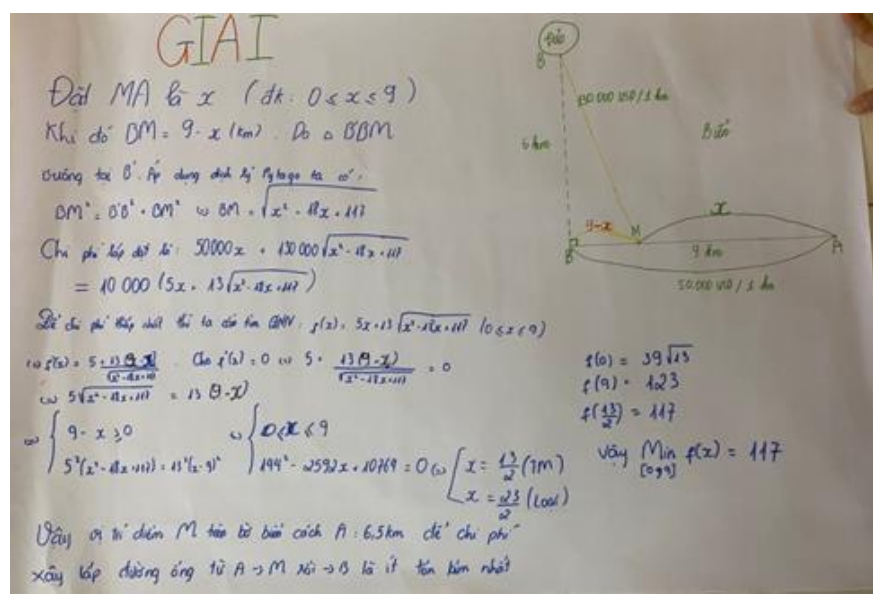

Figure 11. Products of group 2

These results show that they were more active and active in thinking and giving answers. In question 5, most of the students gave the correct answer (94.12\%).

In the discussion and working sessions of the groups, through observing the classroom, we see that the students work very seriously and responsibly. Each individual is very excited and completes their task well. They are very willing to support the group leader to represent their group to present in front of the class. Besides, the teacher also suggested that the students prepare to ask some questions to the other group when their group presents. The products of the groups are carefully presented on an A0 sheet of paper, which proves that the students have prepared well, have made a lot of effort, and tried to complete the assigned tasks (see Figures 10-13).

Under cooperation and serious teamwork, all four groups came up with a strategy to solve the situation for their group. Thereby showing

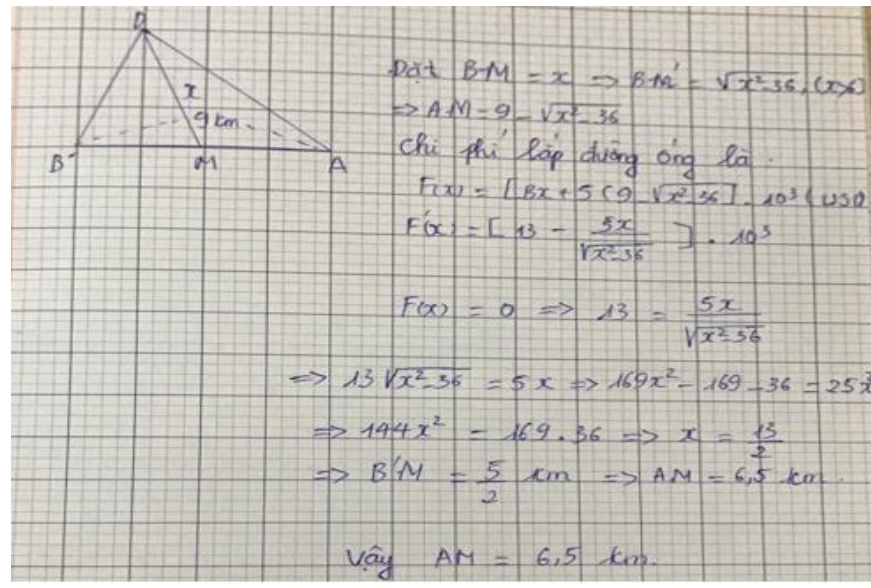

Figure 12. Products of group 3

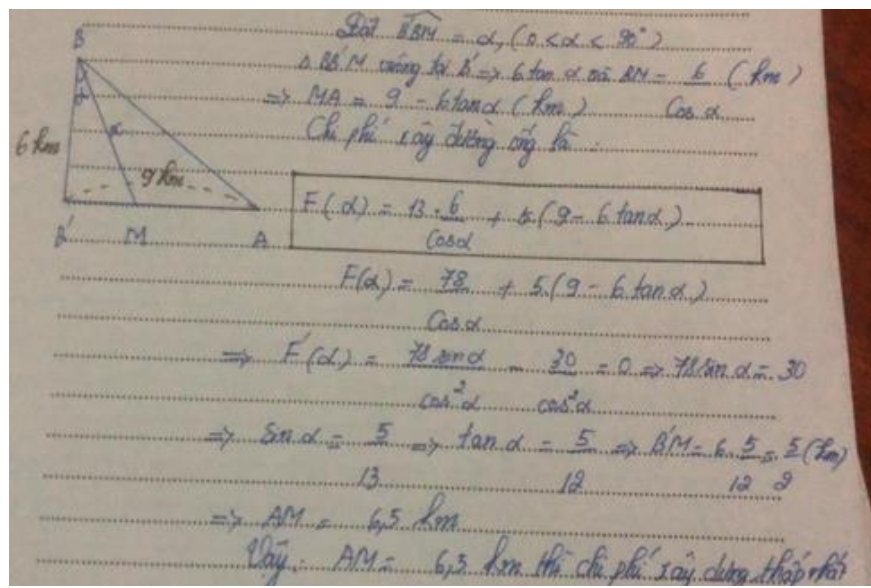

Figure 13. Products of group 4

the positive aspects of the designed learning activities. Through the guidance and control of the teacher, these results were presented to the whole class by representatives of groups 1 (see Figure 14). This activity aims to give students the opportunity to present, give their personal opinions and debates, from which they will receive reasonable adjustments in the problem-solving strategy from the teacher. This is also a good opportunity for them to absorb knowledge and understand the lesson more deeply.

In addition to giving a specific model ("model of") for the initial situation, they also came up with a general model ("model for"), (see Figure 15) that can be applied for a class of similar situations. This activity is based on the level principle in teaching according to RME theory, by building a strategy and a specific model for the initial situation, students gradually form logical thinking and reasoning to It is possible to build a general model for dealing with similar situations. 


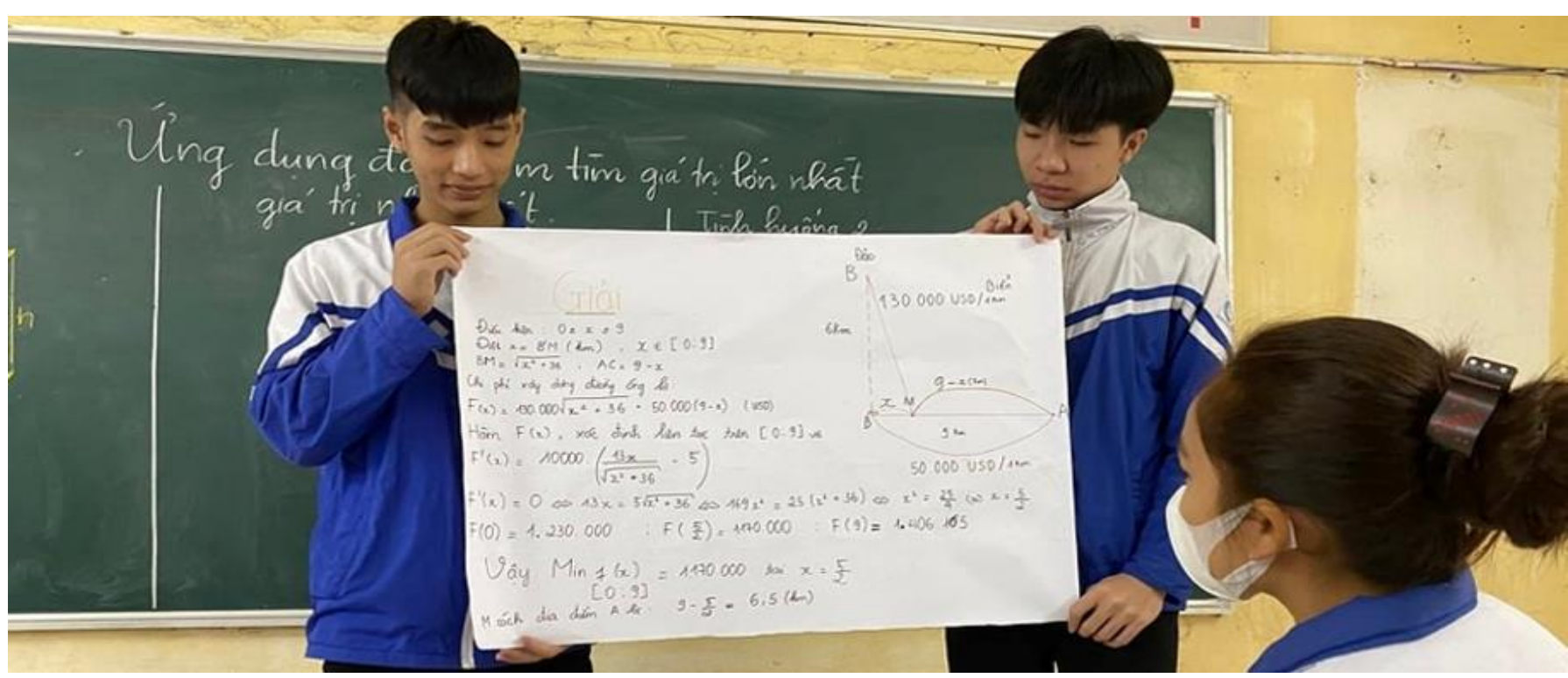

Figure 14. Presentation of group 1

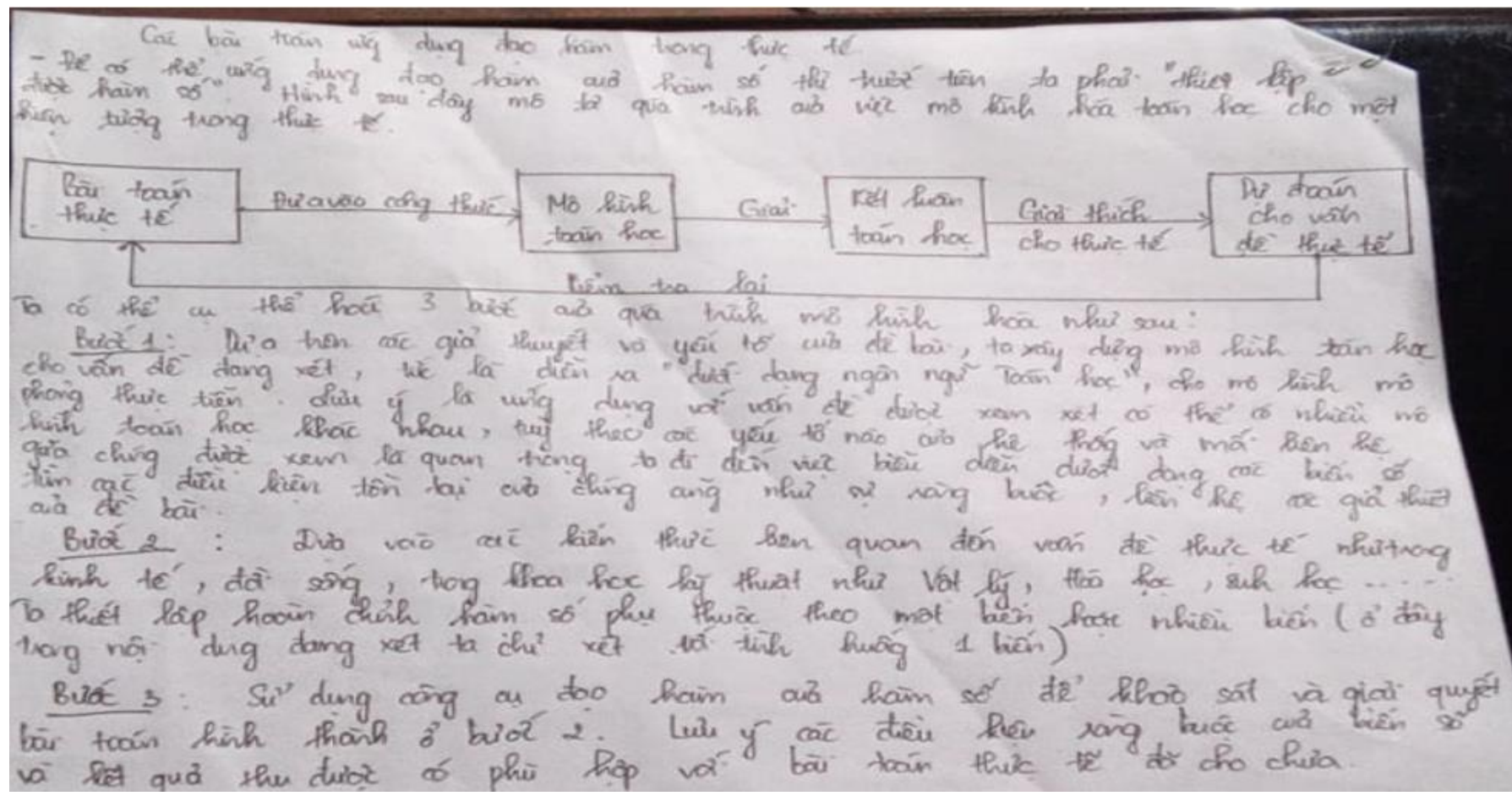

Figure 15. "Model for" (students build on their own)

This is very important in forming and developing "mathematization" competence for students when solving practical problems.

\section{CONCLUSIONS AND RECOMMENDATIONS}

In the research that we have done, the process of designing math lessons using RME method and RME-based teaching model has been proven quite successfully. From experimental teaching, we have found that in order for RME-based teaching to be effective, teachers must be well prepared and require a large investment of time. First, it is important for teachers to be careful in choosing teaching situations. The selected context must be reasonable, both close to reality and able to create the mathematical knowledge that students need to learn. Next, teachers need to prepare a system of guiding questions to help students build "model of" and "model for" step by step. Finally, teachers need to formally introduce the mathematical knowledge that students acquire after the course of learning activities.

Through the situations designed in the article, we see that when faced with real-life situations, students may not be familiar with it at first because they feel it is quite foreign to exercises with purely mathematical content. This makes them curious and sees that it is necessary to explore, so when they are given specific tasks, most are very enthusiastic, attentive, trying to do well. At first, doing group activities can be noisy and lack concentration, but under the control of the teacher, the class is taken very seriously and students participate actively and enthusiastically. Participating in group activities is an opportunity for students to practice and develop teamwork skills, 
cooperation capacity. Moreover, presenting results in front of the class will help them be more confident in expressing their views in front of a group, through which their presentation skills will improve and develop.

Although our study was a case study, with positive results, we believe that RME has positive effects on students' attitudes, problem solving, interest in learning, or other aspects related to learning mathematics. Thus, based on RME, teaching can completely meet the goal of improving the practicality of teaching mathematics in the coming period of Vietnam.

Funding: This research is funded by Vietnam National Foundation for Science and Technology Development (NAFOSTED) under grant number 101.02-2015.10.

Declaration of interest: Author declares no competing interest.

Data availability: Data generated or analysed during this study are available from the author on request.

\section{REFERENCES}

Bakker, A. (2004). Design research in statistics education: On symbolizing and computer tools [Doctoral dissertation, Utrecht University].

de Lange Jzn, J. (1987). Mathematics, insight and meaning: Teaching, learning and testing of mathematics for the life and social sciences. OW $\&$ OC.

de Lange Jzn, J. (1996). Using and applying mathematics in education. In A. J. Bishop, K. Clements, C. Keitel, J. Kilpatrick, C. Laborde (Eds.), International handbook of mathematics education: Part 1 (pp. 4998). Kluwer.

Fauzan, A. (2002). Applying realistic mathematics education (RME) in teaching geometry in Indonesian primary schools [Doctoral dissertation, Universiteit Twente].

Fauzan, A. (2013). Pengaruh pendekatan RME dan kemandirian belajar terhadap kemamampuan matematis siswa [The effect of the RME approach and learning independence on students' mathematical abilities]. Prosiding Semirata FMIPA, 1(1), 7-14.
Franchini, E., Lemmo, A., \& Sbaragli, S. (2017). The role of text comprehension in the process of mathematizing and modelling. DdM Didattica della Matematica. Dalle Ricerche alle Pratiche D'aula [DdM Mathematics Education. From Research to Classroom Practices], 2017(1), 38-64. https://doi.org/10.33683/ddm.17.1.3

Freudenthal, H. (1973). Mathematics as an educational task. Springer. https://doi.org/10.1007/978-94-010-2903-2

Freudenthal, H. (1983). Didactical phenomenology of mathematical structures. Springer.

Freudenthal, H. (1991). Revisiting mathematics education: China lectures. Springer.

Gravemeijer, K. (1994). Developing realistic mathematics education [Phd thesis, Eindhoven University of Technology].

Gravemeijer, K. (2004). Emergent modeling as a precursor to mathematical modeling. In W. Blum, P. L. Galbraith, H.-W. Henn, M. Niss (Eds.), Modelling and applications in mathematics education (pp. 137-144). Springer. https://doi.org/10.1007/978-0-38729822-1_12

Gravemeijer, K., \& Cobb, P. (2006). Design research from the learning design perspective. In T. Plomp, \& N. Nieveen (Eds.), Educational design research. Routledge.

Gravemeijer, K., \& Doorman, M. (1999). Context problems in realistic mathematics education: A calculus course as an example. Educational Studies in Mathematics, 39, 111-129. https://doi.org/10.1023/ A:1003749919816

Treffers, A. (1978). Wiskobas doelgericht [Wiskobas goal-directed]. IOWO, Utrecht.

Treffers, A. (1987). Three dimensions. A model of goal and theory description in mathematics instruction. The Wiskobas project. Reidel. https://doi.org/10.1007/978-94-009-3707-9

Treffers, A. (1991). Realistic mathematics education in the Netherlands. 1980-1990. In L. Streefland (Ed.), RME in primary school. Freudenthal Institute.

Whittles, K. (2007). Cryptology: A didactical transposition into a grade 10 school mathematics classroom $[\mathrm{PhD}$ thesis, University of the Western Cape].

Zulkardi, Z. (2010). How to design mathematics lesson based on the realistic approach? https://repository.unsri.ac.id/6362/1/rme.html 